\title{
Enhancing Satellite Oceanography-Driven Research in West Africa: a Case Study of Capacity Development in an Underserved Region
}

\author{
Ebenezer S. Nyadjro ${ }^{1,2}$ (D) Brian K. Arbic ${ }^{3}$. Christian E. Buckingham ${ }^{4} \cdot$ Paige E. Martin $^{5,6} \cdot$ Edem Mahu $^{7}$. \\ Joseph K. Ansong ${ }^{8} \cdot$ Johnson Adjetey $^{9} \cdot$ Elvis Nyarko $^{9} \cdot$ Kwasi Appeaning Addo $^{7}$
}

Received: 11 February 2021 / Revised: 8 June 2021 / Accepted: 21 June 2021 / Published online: 7 July 2021

(C) The Author(s), under exclusive licence to Springer Nature Switzerland AG 2021

\begin{abstract}
Marine business and resources play a major role in the economics and way of life in coastal West African countries. Such countries see great profitability from their marine resources while also facing challenges that come with a bordering sea. Despite this fact, there has been limited research into the optimal way for West African Coastal States to coexist with, and sustainably use their marine resources, a research deficit that is mainly due to a lack of infrastructure for in-situ work, lack of capacity development, and comprehensive datasets to undertake oceanographic research. The Coastal Ocean Environment Summer School in Ghana (COESSING; www.coessing.org) was developed to help meet some of these challenges. Each summer since 2015, ocean scientists (e.g., biologists, chemists, physicists, hydrologists) from the USA and Europe have collaborated with West African colleagues to lead a week-long intensive summer school in Accra, Ghana, alternating in location between the Regional Maritime University and the University of Ghana. The school receives in excess of 100 participants drawn from universities, government agencies, and the private sector organizations, mainly from Ghana and neighboring Liberia, Nigeria, Togo, and Benin, among others. The format of the school includes morning lectures, afternoon field trips, and hands-on laboratory exercises and one-onone coaching of students. Important to the COESSING program is the satellite oceanography component which introduces participants to the extensive and often free, remotely sensed oceanographic datasets. Participants develop skills that allow them to access, process, and analyze these datasets in order to better understand regional oceanographic phenomena, such as upwelling, pollution, habitat characterization, sea level rise, and coastal erosion. Following the school, facilitators keep in touch with program participants, helping them acquire and analyze data for their studies, dissertations, and often graduate school applications, etc. In summary, schools such as COESSING are critical not only for science in the region but for the global ocean community as such training develops eager, bright minds while leading to improved regional observing and modeling strategies in severely under-sampled seas. Here, we describe a unique case in which satellite oceanography has led to such outcomes for countries bordering the Gulf of Guinea, West Africa.
\end{abstract}

Keywords COESSING $\cdot$ Satellite oceanography $\cdot$ West Africa $\cdot$ Capacity development $\cdot$ Upwelling $\cdot$ Python

Special Issue: "Earth Observation Information Application in the West African Sub-region."

Ebenezer S. Nyadjro

esn31@msstate.edu

1 Northern Gulf Institute, Mississippi State University, 1021 Balch Blvd, Stennis Space Center, Mississippi, MS 39529, USA

2 NOAA National Centers for Environmental Information, Stennis Space Center, Mississippi, MS, USA

3 Department of Earth and Environmental Sciences, University of Michigan, Ann Arbor, MI, USA

4 IUEM / LOPS / Université de Bretagne Occidentale, Plouzané, France
5 Lamont-Doherty Earth Observatory, Columbia University, Palisades, NY, USA

6 Research School of Earth Sciences, Australian National University, Canberra, Australia

7 Department of Marine and Fisheries Sciences, University of Ghana, Legon, Accra, Ghana

8 Department of Mathematics, University of Ghana, Legon, Accra, Ghana

9 Regional Maritime University, Accra, Ghana 


\section{Introduction}

The coastal zone (i.e., 15 miles seawards from the coast) is of important ecological and economical benefit, providing ecological habitats (e.g. mangroves, salt marshes, lagoons, and estuaries), fisheries, tourism, settlements, transport, and industries (e.g. oil, and gas) [2, 11, 23, 29]. Thirteen of the sixteen West African nations have coastline, and the West African coastline stretches 3480 miles from Mauritania to Nigeria (Fig. 1). The population of West Africa is $\sim 403$ million of which $\sim 125$ million people ( $31 \%$ of the West African population; $51 \%$ of the urban population of the coastal countries) live in the coastal zone [3]. The resources from the coastal zone provide $56 \%$ ( $\$ 345$ billion) of the West African Gross Domestic Product [39]. Recent studies [e.g., 11, 29] have shown overcapacity and dwindling marine resources due to increased pressure on fisheries and other marinebased resources. Overfishing and illegal, unreported, and unregulated (IUU) fishing have all been reported at alarming proportions across West African coastal countries with IUU accounting for an annual loss of $\$ 2.3$ billion [8, 21, 29]. Consequently, there is the need for data-driven decision-making for resource management and sustainable use [9, 17]. These needs are consistent with the goals of the United Nations' 2021-2030 international Decade of Ocean Science for Sustainable Development [32].

The West African ocean region is presently the leading hotspot for global piracy activities, with the focus having shifted from the Indian Ocean in recent years [4]. Earth observation data can be used to monitor vessel activities and to enhance maritime security in the West African subregion [4, 35]. Coastal pollution from thermal plants, oil spills, plastics, and other wastes have become major environmental issues of the recent decade $[1,27]$. Issues of flooding and coastal erosion have been increasing in the subregion with an estimated reduction of the coastline at a rate of $\sim 2 \mathrm{~m}_{\text {year }}^{-1}[3,12$, 13]. Coastal habitats such as mangroves have been under threat from both humans and climate, demanding increased research to understand and manage these issues and to safeguard coastal vulnerability and wildlife $[2,19]$. The oceans constantly interact with the atmosphere, such that the ocean and atmosphere both influence the dynamics of the other [22]. The West African monsoon drives weather and climatic variabilities in the subregion [22]. With agriculture being the main source of employment and a major source of foreign exchange earnings, there is a critical need to study weather and climatic patterns to better inform farmers, agriculture service providers (e.g., extension officers and agrometeorologists), and policy makers [34]. Such studies could benefit from the extensive, freely available satellite data.

While the needs of the West African coastal region are widely recognized, the available expertise required to address these needs is often limited. Moreover, human and material resources required for oceanographic research are limited, further hampering data-driven oceanographic and atmospheric decision-making. The Coastal Ocean Environment Summer School in Ghana (COESSING; www.coessing.org) was formed in 2015 to help address these demands. In this study, we report on the activities of the COESSING, with emphasis on the satellite oceanography training module. The goals, structure, successes, and challenges of the module are discussed.

\subsection{Capacity Development}

[24] defined capacity development in developing countries as "the provision of training to scientific staff and students as well as the provision of tools and training to policy makers
Fig. 1 Map of West Africa. Only Burkina Faso, Mali, and Niger are landlocked

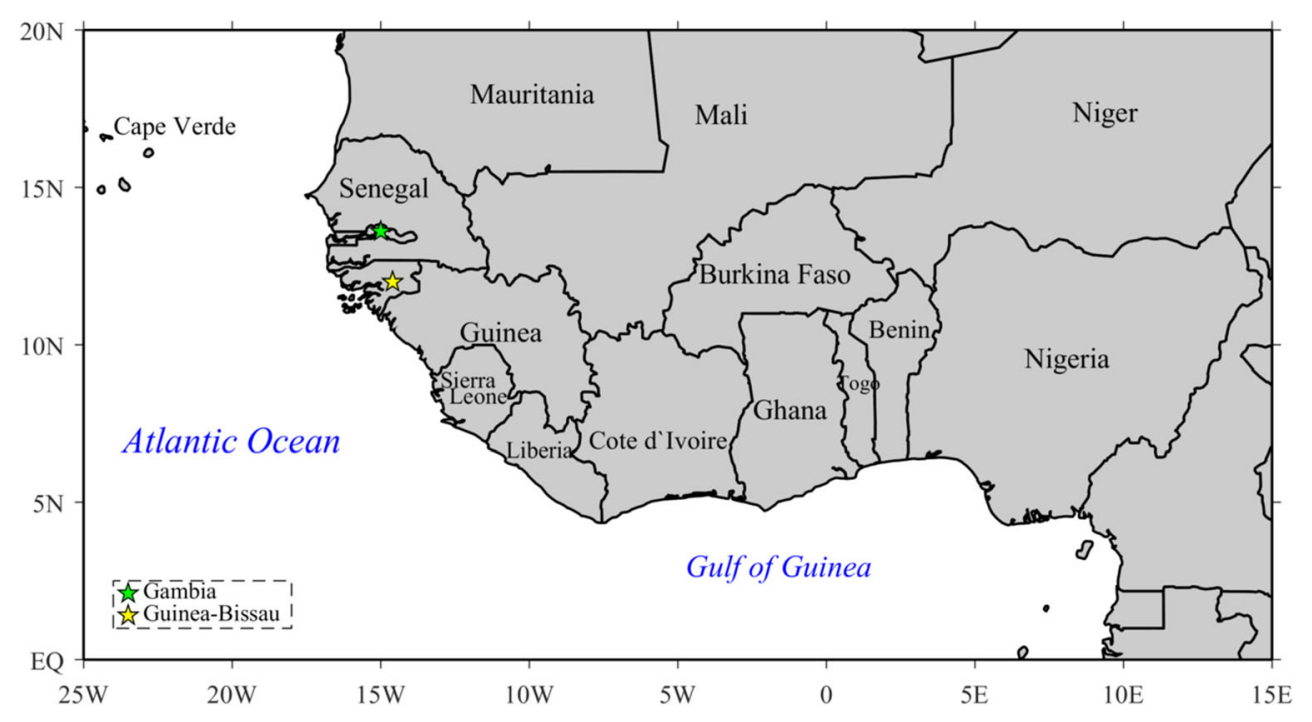


to enable them to collect, and make use of data, products and services, as part of a long-term strategy to ensure that the skills and knowledge acquired are applied to the development of marine science and policy in those countries." Building local capacity ensures relevance and ownership and the development of tools that are effective within a well-niched, socioeconomic context $[19,20,25]$. Due to a limited number of local expertise and financial support for research vessels, most of the sea-going oceanographic research in West African waters are initiated by foreign countries, especially France and the USA.

Summer schools are one of the effective ways to build capacity in geosciences. Summer schools bring together students, early career professionals and experts for 1-2 weeks to focus on selected topics of interests. In addition to the exchange of knowledge that takes place within such settings, summer schools can also lead to networking which enhances future research collaborations and career development [25, 30]. The COESSING was formed to help build oceanography capacity in the West African subregion, increase research outputs, and encourage and aid participation in international meetings and conferences. To achieve these objectives, the COESSING carefully considers and applies best capacity development practices. These include selecting the right suite of instructors with the ability to transfer knowledge and effectively apply practical use, selecting a blend of participants that ensure ability to gain from the training, and apply the knowledge acquired while ensuring balance among gender, career stage, institution, and geography [15, 16, 24].

In addition to general training in oceanography, geology, and fisheries, there is specialized training in satellite oceanography which includes a focused, in-depth component where a small group of students is taken through hands-on exercises. Topics of interest to the subregion such as upwelling, coastal erosion, sea level rise, and pollution are used for satellite oceanography training. Past emphasis has included coastal upwelling in the Gulf of Guinea (GoG) and variability of sea surface salinity in the Congo River estuary.

\subsection{Satellite Oceanography}

Satellite oceanography is a component of earth observation which is the "process of acquiring detailed information about the physical, chemical and biological systems of the planet" [19]. It entails obtaining reliable information about the ocean through "recording, measuring and interpreting imagery and digital representations of energy patterns derived from noncontact sensor systems" [14]. The emphasis on satellite datadriven research for West Africa is primarily because of the low cost to access data. Most satellite-derived data are freely available and offer expansive, repetitive measurements for many research studies [26]. It cost $\$ 5000$ per day (excludes fuel and other consumables) to sample the West African waters on board a research vessel [Nigerian Institute for Oceanography and Marine Research, personal communication, January 18, 2021].

Earth-observing satellites provide distributions of a variety of ocean surface properties in exquisite detail which allow the true spatial structure of the ocean to be examined [19]. At present, this is not possible with other means of data acquisition such as in-situ measurements and numerical ocean models. For example, oceanographic research ships tend to avoid harsh weather conditions and hazardous, piracy-prone regions. Also, drifting buoys tend to poorly sample regions characterized by divergent currents. In contrast, satellites yield extensive datasets which can be used to initialize and run numerical models and to perform ocean and weather forecasts [7, 28, 33].

Satellite oceanography, however, is not without its limitations. It can only observe some of the ocean's variables and properties. Additionally, measurements can be corrupted by the atmosphere and poor weather. Moreover, for targeted process studies, the satellite needs to be at the right place and time in order to make these measurements. Perhaps, the most limiting aspect of satellite oceanography, however, is the inability of satellites to sense below the ocean surface. Nevertheless, there are subsurface oceanic processes that manifest in the surface ocean. For example, the upwelling of subsurface waters has surface signatures such as cold waters, low sea surface heights, high chlorophyll, and high sea surface salinity [10, 36]. These parameters can respectively be measured remotely by radiometers (e.g., the Moderate Resolution Imaging Spectroradiometer (MODIS) aboard the Aqua satellite and the Visible Infrared Imaging Radiometer Suite (VIIRS) aboard the Suomi/NOAA-20 satellite), altimeters (e.g., Jason 3 and Sentinel-6 Michael Freilich satellites), ocean color (e.g., VIIRS aboard NOAA-20 satellite and Ocean and Land Color Imager (OCLI) aboard Sentinel 3 satellite), and salinity satellites (e.g., Soil Moisture and Ocean Salinity (SMOS) and Soil Moisture Active Passive (SMAP) satellite missions).

Several African countries have demonstrated interests in satellites for earth observations and research and, in some cases, have launched their own satellites into space. At present, eleven African countries have launched 36 satellites [38]. For example, Algeria launched the ALSAT-2B in 2016, Egypt launched EGYPTSAT-A in 2019, Ghana launched GhanaSat1 in 2017, Nigeria launched NigeriaSat-2 in 2011, and South Africa launched ZACUBE-2 in 2018 [38]. GhanaSat-1 and ZACUBE-2 are so-called CubeSats which are miniature satellites (typically less than $3 \mathrm{lbs}$. per unit), quick to develop, offer independence and control, and relatively affordable (typically $\$ 600,000$; compared with $\$ 120-350$ million for a conventional satellite), thus offering the exploration of new technologies with relative ease. While the cost to develop and launch conventional satellites on the scale of the US National Aeronautics and Space Administration (NASA) and the European Space Agency (ESA) is beyond the 
financial abilities of African countries, the opportunity to use CubeSats can generate interest in the potential of earth observations for research and data-driven environmental decisionmaking. More importantly, the ability to analyze the data from these miniature satellites and conventional satellites is paramount. GhanaSat-1 was an initiative of the All Nations University (ANU), a Ghanaian private university. The launch of the satellite generated considerable national and international media attention [e.g., BBC News-https://www.bbc. com/news/world-africa-40538471]. At its launch, Ghana was facing the serious issue of "galamsey," a local coinage for the illegal mining of gold and other minerals in water bodies, which dangerously polluted rivers (a major source of drinking water). The potential use of drones and data from GhanaSat-1 was one of the suggestions for the monitoring and study of environmental impacts of "galamsey."

\section{Overview of the COESSING}

COESSING was founded by Prof. Brian Arbic, of the University of Michigan (U-M). In August 2014, Prof. Arbic and Dr. Joseph Ansong (formerly of U-M and now at the University of Ghana) scouted possible institutions in Ghana to run the program [6]. The school is free of charge; participants only need to cover the costs of transport to the school venue. Participants are provided with accommodation and meals throughout the school duration. Funding for COESSING has come from a variety of sources, including the US National Science Foundation, U-M (e.g., MCubed, African Studies Center (ASC), ASC Science, Technology, Engineering, and Mathematics (STEM)-Africa Initiative, Michigan Sustainability Cases of the School of Natural Resources, and the Environment, and the Office of Global and Engaged Education), the International Centre for Theoretical Physics (ICTP) in Trieste, Italy, and numerous Ghanaian sources (e.g., Ghana Ports and Harbors, Ghana Maritime Authority, etc.).

The first COESSING summer school was held in August 2015 at the Regional Maritime University (RMU) with approximately fifty participants, four US-based resource persons and one RMU faculty member. It has since been held each summer alternating between two campuses: RMU (Fig. 2) and the University of Ghana (UG), with the exception of the 2020 school, which was held online owing to the COVID-19 pandemic. It is noteworthy that UG is a full-fledged research university, with a Department of Marine and Fisheries Sciences, while RMU's mission is dedicated to the training of maritime professionals such as seafarers. This unique difference between the two institutions allows COESSING to reach a diverse group of interested participants.

While the first COESSING was only lecture-based, subsequent schools have evolved to include field trips to local beaches and lagoons, boat trips with instrument deployments in the coastal waters (Fig. 3), laboratory experiments and hands-on training (Fig. 4), small group interactions, mini-projects, and poster and oral presentations of project results. The mini-projects span many forms, including students' own theses or pertinent topics of interest to the West African subregion. Data from the harbor/boat trips are collected via satellite and are then used to run laboratory exercises.

Subjects covered during COESSING include coastal ocean dynamics, biogeochemistry, satellite oceanography, field oceanography, numerical ocean modeling, data analysis techniques, oil and gas basin development, fisheries management, pollutant dispersal, and graduate school opportunities and application strategies. The school has led to ongoing collaboration between RMU and the University of Southern Mississippi to develop a Master of Science degree-granting program in hydrography at RMU. When established, satellite oceanography will be a component of the training of hydrographers in the West African subregion. There have been COESSING students who have obtained graduate school admissions to schools in their home countries and abroad, as a result of interactions between COESSING instructors and participants.

The number of COESSING applicants has grown greatly over the years. For the 2019 school, for example, there were over 400 applicants of which only about 125 were selected to attend the school (Fig. 5). Most applicants were from Ghana, but a non-negligible number also came from Nigeria, Liberia, Togo, Côte d'Ivoire, Mali, South Africa, Cameroon, and Benin. The background of applicants was also diverse, including undergraduate students, graduate students and faculty members from universities, and personnel from government agencies and private sector organizations (Fig. 5). For the nonstudent groups of applicants, COESSING provides an opportunity to gain continuous training which is important for their career development and promotions. Resource persons for COESSING are drawn from universities and research institutions in the USA, Italy, France, and the host country, Ghana. The US participants have included several undergraduates from U-M and Hampton University and graduate students from U-M, the Massachusetts Institute of Technology (MIT)/Woods Hole Oceanographic Institution (WHOI) Joint Program, Oregon State University (OSU) and the University of California Berkeley (Table 1; [6]).

\section{COESSING Satellite Oceanography Module}

Studies [e.g., 5, 20, 24] suggest that for an effective capacity building in developing countries, it is important to include local scientists in the teaching in order to provide relevant expertise and to act as role models to early career scientists after the training programs have ended. Also, instructors need 
Fig. 2 Participants and resource persons during the 2019

COESSING at the Regional

Maritime University

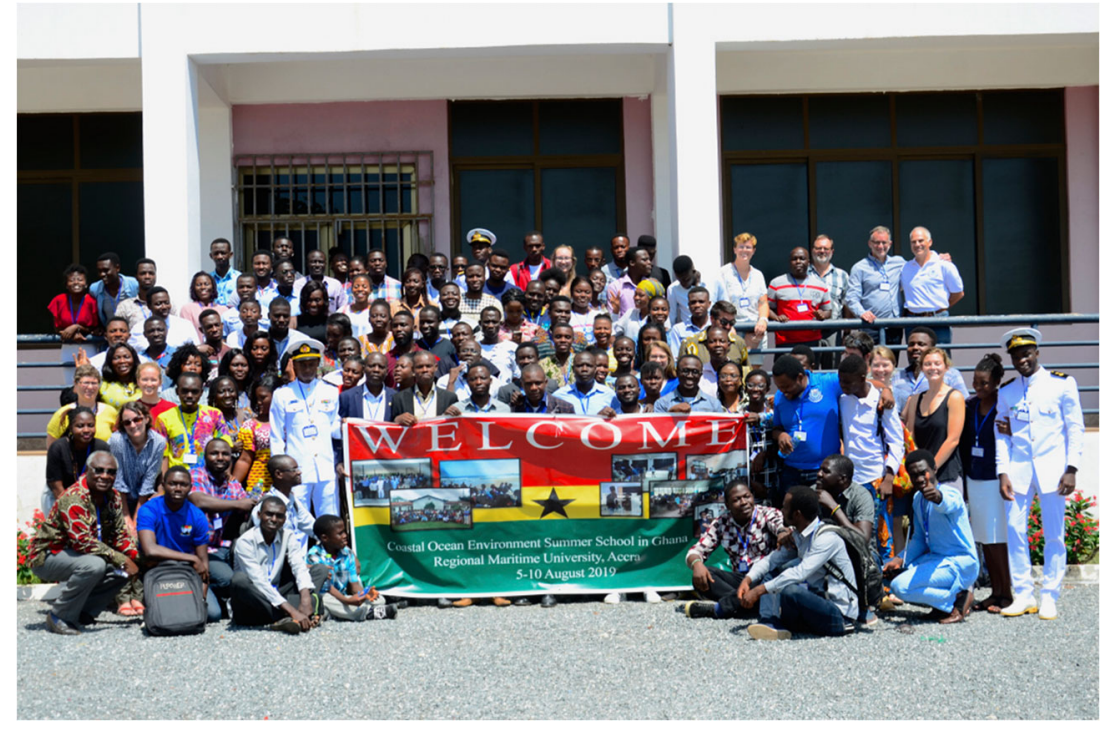

to adjust their teaching styles to accommodate the educational practices of their local hosts. Fortunately, our COESSING satellite oceanography instructional team includes a Ghanaian native which makes this module quite popular with participants. Although the focus of the COESSING satellite oceanography module is on the coastal ocean, the skills and techniques taught in this module are applicable to other areas such as meteorology, agriculture, hydrography, limnology, mining, forestry, and water resource management.

The constructivist approach to learning has been suggested as an effective pedagogy for the geosciences [5, 31] and is adopted in the COESSING satellite oceanography module. In this approach, students learn scientific ideas by building their own knowledge using inquiry-based exercises. The constructivist approach to these exercises is different from traditional laboratory exercises because it is designed to make the student approach the problem just as an experienced researcher will do-i.e., using multifaceted data and approaches, testing different hypotheses, and collaborative thinking. The curriculum of COESSING satellite oceanography module is designed to blend theory and hands-on training. It emphasizes hands-on training since our inquiries have shown that most of the teaching in West Africa is theoretically based and students prefer to gain substantial practical training. Lectures are held in the mornings. Topics treated under the module include history of remote sensing, physics and principles of remote sensing, radiometry, altimetry, scatterometry, and microwave remote sensing (e.g., synthetic aperture radar-SAR). In the afternoons, students are taken through practical work and laboratory exercises (Fig. 4). The hands-on training component of the module includes data (i) acquisition and storage, (ii) processing, (iii) visualization and display, (iv) enhancement, and (v) interpretation. Furthermore, we emphasize the synergistic use of multi-sourced satellite data to address pertinent

Fig. 3 A boat trip in the coastal waters of Ghana where oceanographic instruments were deployed. Data were sent back to the laboratory via satellites and used for hands-on training

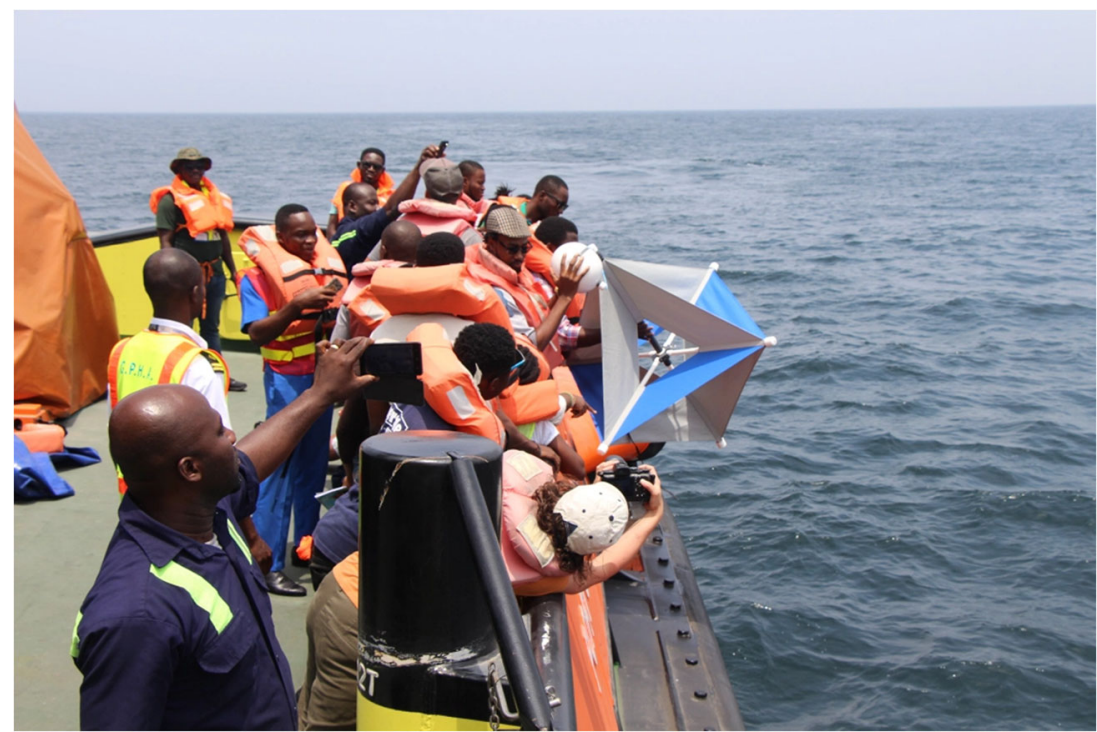




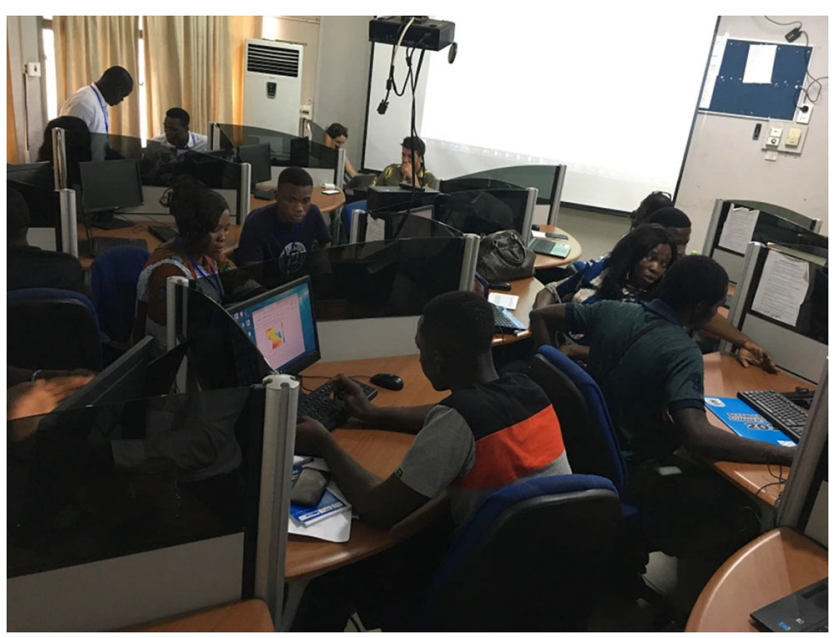

Fig. 4 Participants engaged in a satellite oceanography laboratory session during COESSING 2019

environmental phenomena. For example, in explaining the concept of upwelling in the GoG (discussed below), participants are encouraged to examine sea surface temperature (SST), ocean color, sea level anomaly (SLA), and wind measurements to understand how these variables might vary during the occurrence of the predominant summer GoG upwelling season and their connections to biology and climate (Fig. 6).

\subsection{Python Training}

Key requirements for the successful use of remote sensing data are a capable computer and knowledge of a programming language in order to download, store, manage, process, analyze and visualize these data [19]. While various dedicated software exist for processing remotely sensed data (e.g. NASA's SeaDAS, ESA's BEAM, and United Nations Educational, Scientific and Cultural Organization's UNESCO- Bilko), they are often limited in their ability to handle different and often sizable datasets, perform complex manipulations, and display these results in a meaningful form. Commercial software such as MATLAB® can be prohibitively expensive for many; as an example, a student license costs $\$ 100$, which is well beyond the budget for most African students and researchers. [19] identify the cost of software licenses as the main impediment to developing earthobservation capacity building in most developing countries. Consequently, COESSING strives to adopt Free and Open Source Software (FOSS) such as Ocean Data View (ODV; https://odv.awi.de/), Integrated Data Viewer (IDV; https:// www.unidata.ucar.edu/software/idv/), and Python programming (https://www.python.org/) software for our hands-on training components. Indeed, there are dedicated Python training sessions that are held during COESSING.
These efforts have greatly contributed to the success of the satellite oceanography module.

By combining the use of freely available data and FOSS, students have been able to produce publication-quality plots and execute codes from their own laptops, skills they could take with them after COESSING. The excitement among the school attendees after making their first plots has been astounding. There are numerous examples of participants going back to their home institutions, teaching others Python, and using Python to significantly further their own research. FOSS is an essential step towards broadening participation in geosciences. Although this case study focuses on scientists in developing nations, the arguments apply equally to underprivileged and underserved communities in developed nations, as well.

\subsection{Case Study Laboratory Exercise: One Concept, Multiple Outcomes}

The output from a sample hands-on training exercise shown in Fig. 6 is an ideal example of achieving several geoscience capacity building objectives with one oceanographic phenomenon. This figure shows the variations of SST, SLA, ocean surface winds, and chlorophyll-a during the occurrence of coastal upwelling in the central Atlantic Ocean and northwestern Gulf of Guinea (NWGoG). Coastal upwelling is an important oceanographic and biological occurrence for the subregion. It enhances biological productivity as nutrient-rich subsurface waters are brought to the surface ocean. As the water becomes more productive, abundance of fish, mainly Sardinella aurita, increases [37]. The learning objectives of this coastal upwelling hands-on training exercise include coding in Python, sourcing for earth observing data, examining tools for downloading large datasets and sub-setting, conducting data validation and quality checks, performing basic computations (e.g. data filtering, time series, data smoothing, wavelet analysis, averages, seasonal and interannual anomalies), making publication-quality plots, interpreting oceanographic data outputs, understanding environmental synergies and the various physical parameters that interact to cause upwelling, understanding biological productivity, and learning to predict future upwelling occurrences based on historical patterns.

At the start of this exercise, COESSING participants are shown multiple websites that contain free satellite-derived data. These include the NASA data repository (https://podaactools.jpl.nasa.gov/drive/files), Remote Sensing Systems repository (ftp://ftp.remss.com), the European Union Copernicus climate data store (ftp://my.cmems-du.eu), and the Asia-Pacific Data Research Center data repository hosted at the University of Hawaii Manoa (http://apdrc.soest.hawaii. edu/data/data.php). Participants are trained to read different satellite data formats (e.g. NetCDF, HDF, BUFR, and 


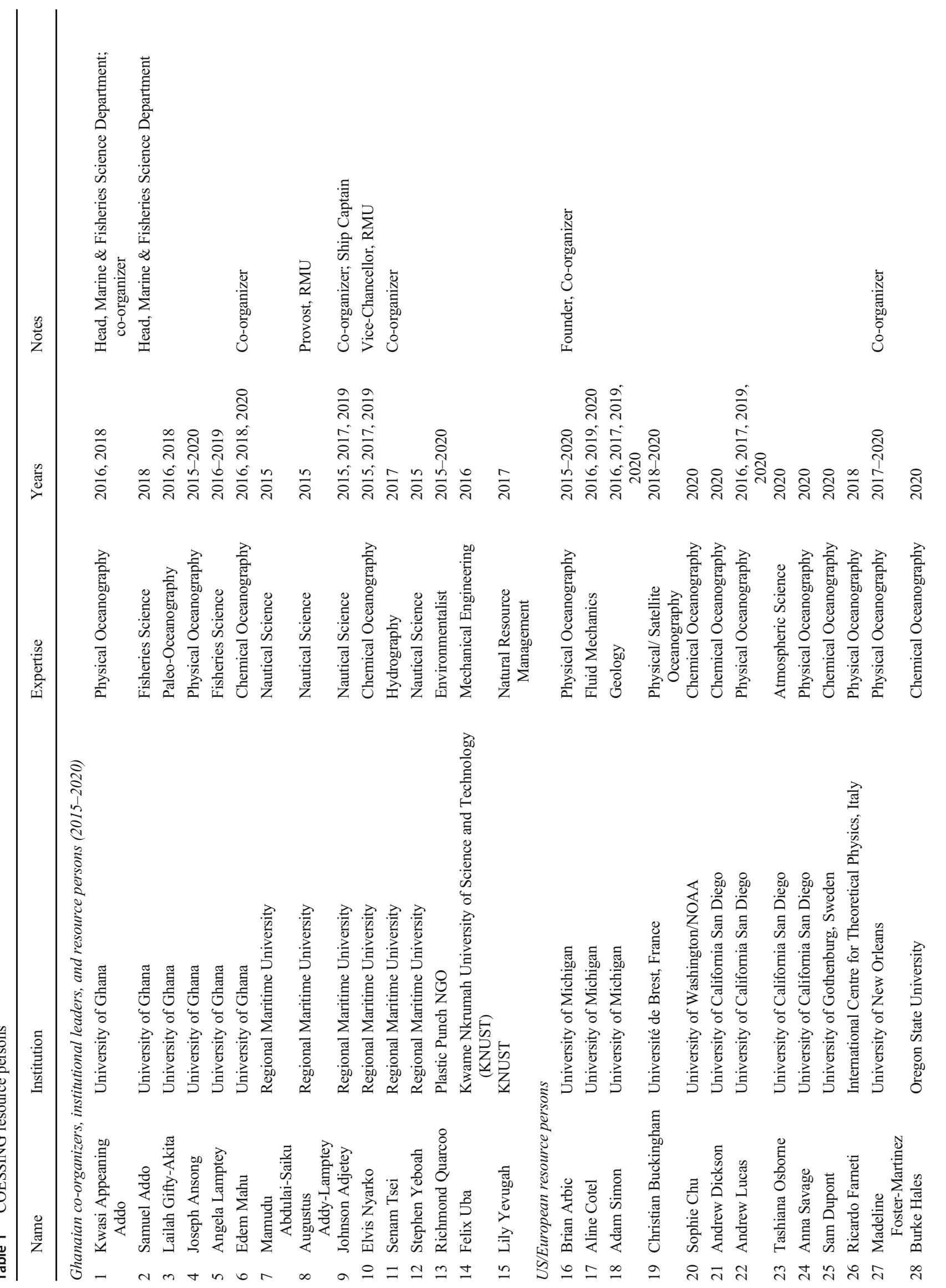




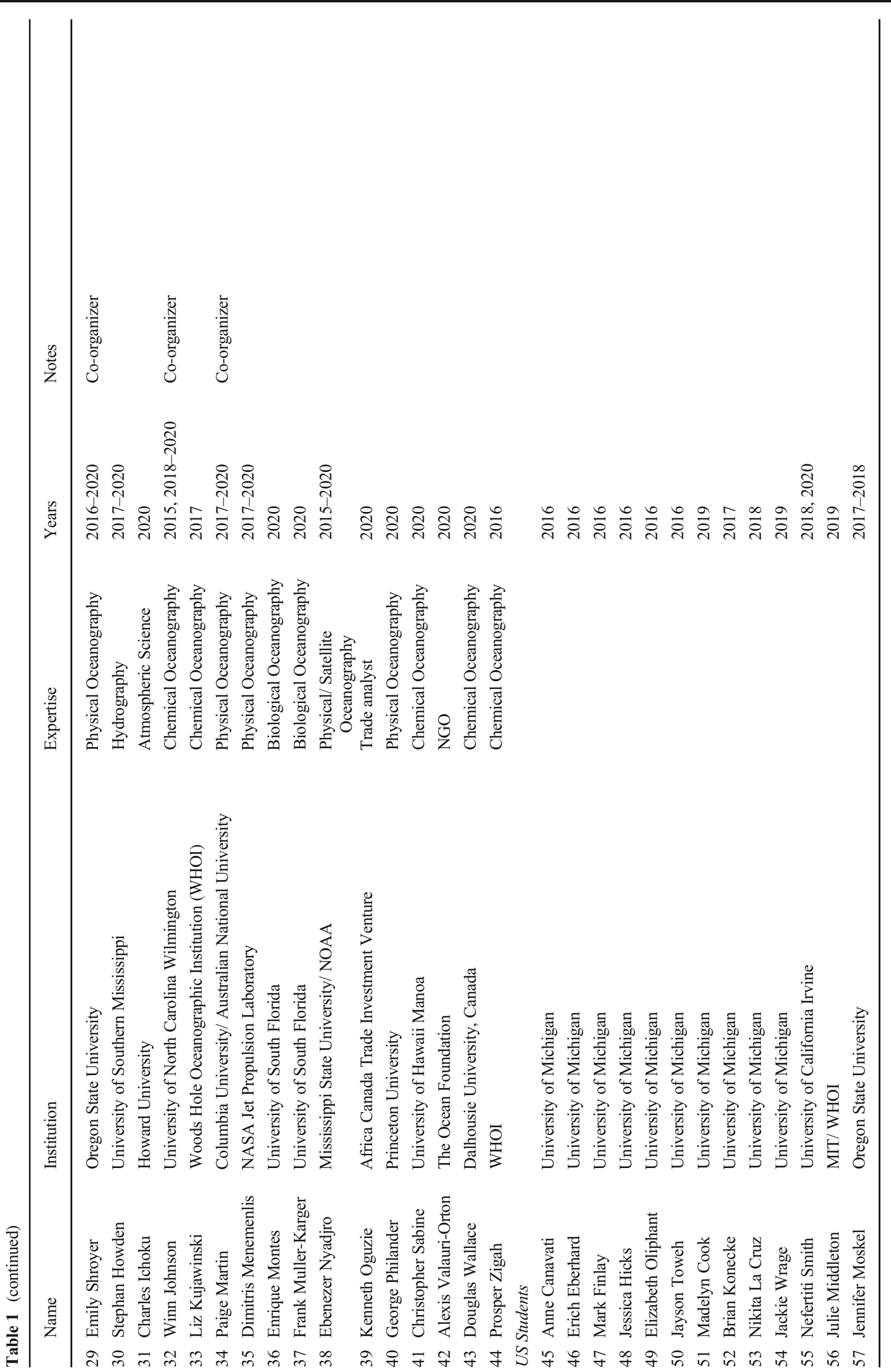


Fig. 5 Career stage of 2019 COESSING participants

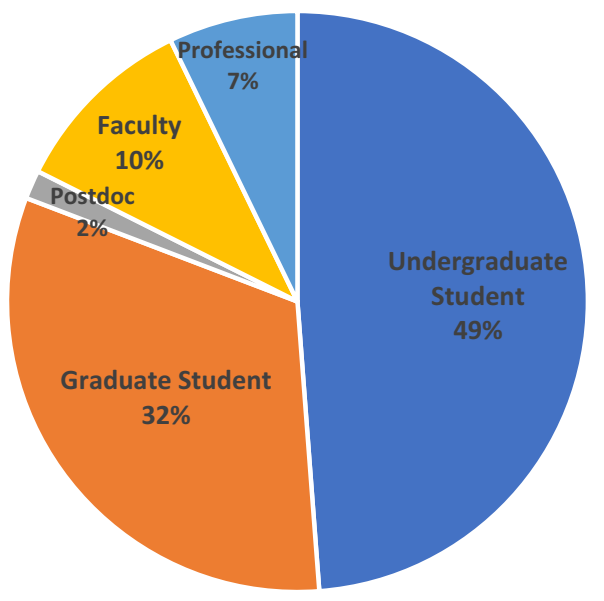

In the NWGoG, between Côte d'Ivoire and the Republic of Benin, a minor upwelling season occurs between December and March and typically lasts for only 3 weeks, while a major upwelling season occurs during the boreal summer in July to
Fig. 6 Using the upwelling phenomenon in the Gulf of Guinea to teach multi-satellite data usage and multiple data analysis techniques. (a) Seasonal anomalies of SST (color shading, ${ }^{\circ} \mathrm{C}$ ), SLA (contours, $\mathrm{m}$; $\mathrm{CI}=$ $0.02 \mathrm{~m}$ ), and surface wind speed (vectors, $\mathrm{ms}^{-1}$ ) in the Central Atlantic Ocean during January. (b) As in (a) but for August. (c) and (d) As in (a) and (b) respectively but for chlorophyll-a $\left(\mathrm{mg} \mathrm{m}^{-3}\right)$. White box in (a) and (b) $\left(10^{\circ} \mathrm{W}-4^{\circ} \mathrm{E}, 3^{\circ} \mathrm{N}-7^{\circ} \mathrm{N}\right)$ shows the northwestern GoG used for time series analysis. (e) Seasonal variation of SST (red line, ${ }^{\circ} \mathrm{C}$ ) and SLA (black line, $\mathrm{m}$ ) spatially averaged in the northwestern GoG box. The strongest correlation between SST and SLA seasonal anomalies (0.71) occurs at zerotime lag. (f) Interannual variation of SST (red line, ${ }^{\circ} \mathrm{C}$ ) and SLA (black line, $\mathrm{m}$ ) spatially averaged in the northwestern GoG box during 1993-2017. The strongest correlation between SST and SLA interannual anomalies $(0.73)$ occurs at zero-time lag
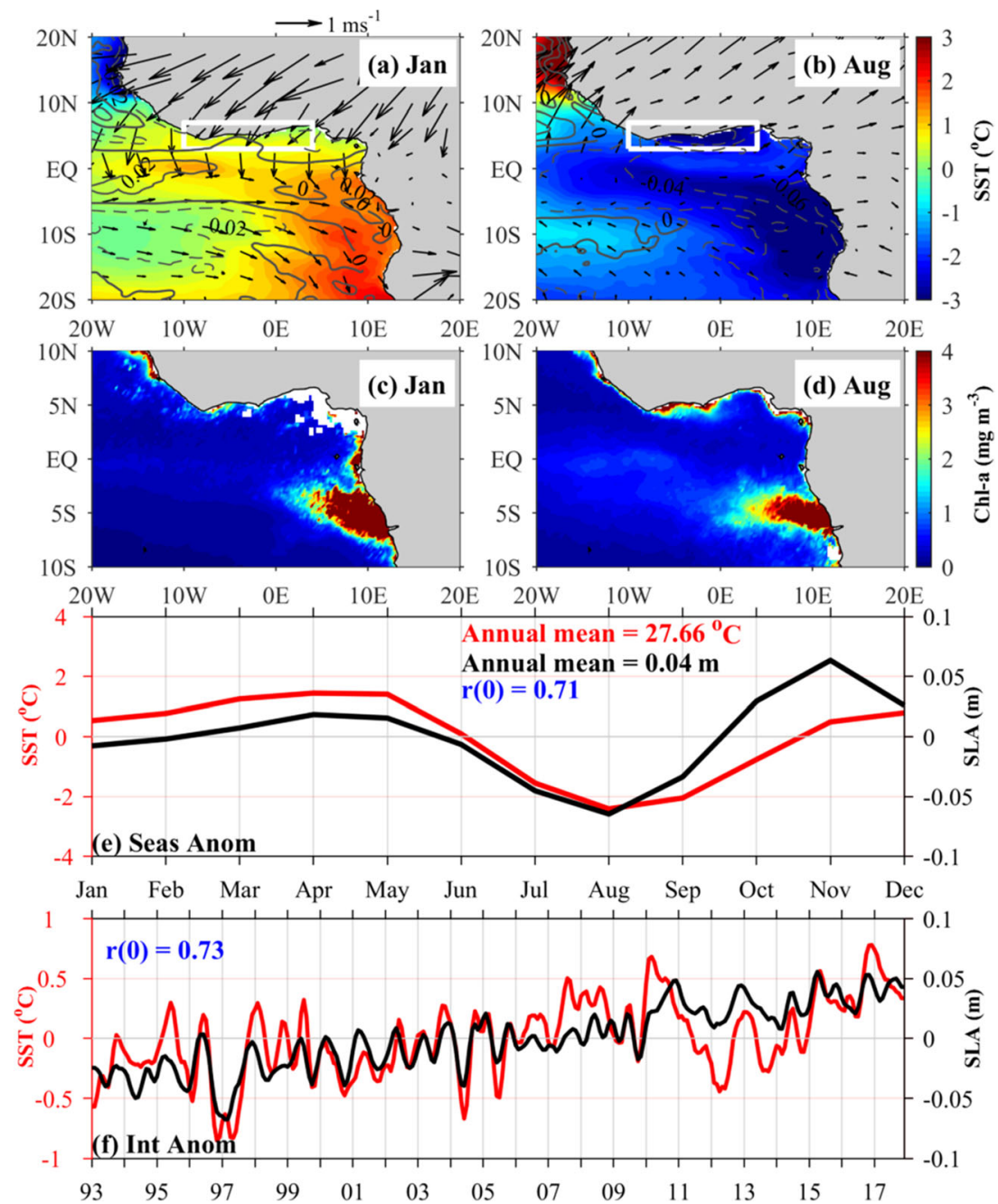
September $[10,36]$. The plots from the exercise (Figs. 6a-e) capture these minor and major upwelling seasons in the NWGoG and how the various satellite-derived surface ocean parameters vary during the seasons. Seasonal anomalies are computed by removing the annual mean from the monthly time series. The SST drops significantly $\left(\sim 2.5{ }^{\circ} \mathrm{C}\right.$ lower than the annual mean), sea level is anomalously lower ( $\sim 0.06 \mathrm{~m}$ lower than the annual mean), and coastal chlorophyll-a increases during the summer upwelling season. By using pseudo-color spatial plots (Figs. 6a-d), participants learn the important concept of effective scientific communication. Pseudo-color plots use color to denote areas of high and low concentrations in the data, allow the data to speak for themselves, and influence the way scientific information is perceived. Overlaying other parameters (Fig. $6 \mathrm{a}, \mathrm{b}$ : SLA as contours and surface winds as vectors) on the pseudo-color plots conveys the concept of data synergy and colocating areas of minimal or maximal occurrence for emphasis. The use of time series plots educates the participants on how to use box-averages to focus on variability and dynamics in a particular geographical area. Figure 6e shows that SST and SLA seasonal anomalies are phase-locked and positively correlated, with the strongest correlation between the pair $(r=0.71)$ occurring at zero time lag; warm water expands and causes sea level to rise while cold water contracts and causes sea level to drop. Computing and analyzing lag correlations teaches the participants about possible interdependence between environmental parameters and time lags that sometimes exist between the influence of one parameter on another.

Basic meteorology and physical oceanography concepts are used to help participants understand air-sea interactions and how these influence dynamics in the ocean. The changes in wind directions prior to upwelling cause the offshore movement of near-coastal surface waters (Figs. 6a, b). According to Ekman theory, the waters will move towards the right of the wind direction in the northern hemisphere. This leads to vertical advection of nutrient-rich, cooler subsurface waters into the surface ocean (Figs. 6b, d). Given the importance of upwelling especially to the fisheries industry [37], as well as to dynamics of air-sea interactions [18], there is the need to perform long-term studies to understand historical trends and to forecast future occurrences. This has however been difficult in the past as in-situ measurements typically do not have extensive temporal coverage. Remote sensing offers a plausible solution. Figure 6 (f) shows the interannual anomalies of SST and SLA in the NWGoG spanning nearly three decades of satellite-derived data. Here, we compute interannual anomalies by subtracting the monthly climatologies from the monthly time series and then smoothing with a 3-month running mean twice to remove intraseasonal variability. Using this plot, we are able to inform participants about the yearto-year variations that occur in the ocean and the possible causes of these long-term variations such as the Atlantic Niño and the El Niño-Southern Oscillation.

\subsection{Evaluating the Impacts and Success Stories}

During the final sessions of COESSING each year, participants are encouraged to make presentations from the handson laboratory exercises and their mini-projects. Here, they exhibit the computer programming skills that they learned, as well as the synthesis and communication of satellitederived ocean information. Upon completion of the school, participants are given questionnaires where among others, they assess the COESSING course contents. Beyond the school, we have seen increased use of satellite-derived data in participants' research, dissertations, and publications. COESSING resource persons have stayed in touch with participants, helping with their theses, research, and building networks. In addition, participants have been mentored and guided in applying and enrolling in graduate programs in their home countries and abroad (e.g. University of North Carolina Wilmington, University of Southern Mississippi, and University of Victoria in Canada).

There have been great testimonies from past COESSING participants (https://coessing.org/testimonials/). For example, Richmond Kennedy Quarcoo, a Nautical Science alumnus from RMU, founder of Plastic Punch NGO and a participant in all COESSING editions said, "the field trip on the tugboat ignited my interest in oceanography since it exposed me to real time methods and measurements. The results compared well to existing chartered depths and made me trust my onboard ship chart even more as a seafarer. Interacting with other participants and instructors together with the well-structured lectures and laboratory exercises gave me more knowledge and insight into my research project." Anne Canavati, an undergraduate research assistant from U-M said, "my two weeks in Ghana assisting with the summer school and completing independent research on electronic waste recycling at Agbogbloshie was incredible and lifechanging. Learning about oceanography topics from leading international scholars during the school as well as meeting and speaking with Ghanaian students, faculty, and professionals greatly enhanced my knowledge of environmental subjects. I am very thankful for this great experience!". Oghenekevwe Oghenechovwen, an undergraduate in Meteorology and Climate Science from the Federal University of Technology Akure, Nigeria said, "at Accra, I explored science with a diverse and optimistic group in a way I never had. The lectures upgraded my knowledge, I developed new skills helpful for analysis from the labs, sailed the Atlantic Ocean for the first time to take measurements, meaningfully dialogued and connected with other participants and instructors, participated in a project on seasonality and drivers of salinity in the Gulf of Guinea. Since I returned to Nigeria, I have improved the quality of my senior thesis and helped co-solve class tasks using Python to analyze meteorological and oceanographic data."

Michelle Clottey, a Fisheries Science PhD candidate from the University of Cape Coast, Ghana said, "my research work 
is centered on conducting stock assessment of some commercially important seabreams from our Ghanaian waters. I wanted to find out how oceanographic data could be linked to the dynamics of this fish stock. I am considering looking at SST, chlorophyll-a and salinity. My problem was how to get access to such data. The summer school made me realize that I could get whatever information I needed from satellite data and didn't have to go through long protocols or procedures to acquire them from the institutions responsible for such data in Ghana". Prof. Rachel Toyosi Idowu, a participant from University of Abuja, Nigeria said, "thanks for your response to the needs of scientists in the developing world. You have left us stronger, more equipped, and more exposed to knowledge in oceanography than we were before the summer school. You have indeed increased and developed my academic skill and capacity building. I have been enriched, fulfilled, and I promise to impart the knowledge to all my students, both graduate and undergraduate, and also encourage other researchers to key into the subsequent summer school programs" (https://coessing.org/testimonials/).

\subsection{Challenges and Future Steps}

Limitations with Internet access negatively impact the effective use of satellite-derived data for environmental decision-making in West Africa. Most satellite data are large and need to be downloaded from remote sites. For capacity building schools such as COESSING, using pre-prepared data helps reduce this impact. For continuous, everyday use however, cloud computing platforms may eliminate the need to download extensive satellite data [24]. Thus, governments will need to improve internet access to universities and research centers to encourage and support remote sensing applications in the subregion.

In 2020, COESSING could not be held in person due to the COVID-19 global pandemic and thus experienced a shift to an entirely online format. While this format was a first for us and posed several logistical challenges (especially the poor internet connectivity in West Africa), we were able to navigate this path and achieved several successes. By using online tools such as Zoom conferencing, YouTube, and Slack, we were able to accommodate more participants than we do with in-person schools, including participants from India, Brazil, and Turkey. We were also able to expand our course contents and introduce new sessions such as panel discussions on Women in STEM and Pathways through STEM. These panel discussions were wellpatronized by participants and therefore offered again in an online mini COESSING during early January 2021.

\section{Conclusion}

Remote sensing offers an opportunity to enhance datadriven environmental decision-making in West Africa.
This progress has been slow due to the lack of capacity development to harness the benefits of the extensive, often free, remotely sourced oceanographic data resources. By organizing COESSING in West Africa since 2015, we have aimed to increase the technical abilities of participants in accessing, storing, processing, analyzing, interpreting, and presenting oceanographic data. COESSING- and the satellite oceanography module in particular- have been well-received by participants and will need to be regularly repeated to sustain the gains made so far in capacity development. A challenge to achieving this objective, however, is access to continuous funding for COESSING. It is hoped that sustained funding will be possible to continue COESSING and to build partner programs across the African continent.

Going forward, efforts will be made to enhance regional collaborations among participating countries, with an emphasis on common priorities of the countries. This could be achieved through collaborations for joint research and proposals, as well as through the establishment of regional centers of excellence in satellite oceanography that could, perhaps, house satellite receiving stations to obtain, process, and make these data available for the African subregion.

Acknowledgments Funding for COESSING has been generously provided by the University of Michigan, the US National Science Foundation, the International Center for Theoretical Physics, Trieste, Italy, and several organizations in Ghana (Ministry of Fisheries and Aquaculture Development, Ministry of Petroleum, Ghana Ports and Harbors Authority, Ghana Shippers Council, and Global Cargo and Freight Forwarding Ltd). Our kind appreciation goes to all resource persons and students who volunteered their time for COESSING. The authors would like to thank the various data sources for the freely available data used in this paper and also during COESSING. Python tutorials developed by COESSING resource persons are freely available at https://coessing.org/coessing-2020-python-resources/. The COESSING YouTube channel is at https://www.youtube.com/channel/ UChiCQrtC6U06ce3u_4aSKAQ. We thank the anonymous reviewers whose comments helped improve the manuscript.

Data Availability In this paper, National Oceanic and Atmospheric Administration (NOAA) Optimal Interpolated SST (OISST) data were obtained from https://www.ncdc.noaa.gov/oisst. NASA SeaWiFS chlorophyll-a data were obtained from https://oceancolor.gsfc.nasa.gov/ 13/. Cross-Calibrated Multi-Platform (CCMP) surface winds data were obtained from http://www.remss.com/measurements/ccmp/. AVISO sea level anomaly (SLA) data were obtained from https://resources.marine. copernicus.eu/?option $=$ com_csw $\&$ view $=$ details $\&$ product_id $=$ SEALEVEL_GLO_PHY_L3_NRT_OBSERVATIONS_008_044.

\section{Declarations}

Conflict of Interest Authors declare no financial and competing interests. 


\section{References}

1. Adika SA, Mahu E, Crane R, Marchant R, Montford J, Folorunsho R, Gordon C (2020) Microplastic ingestion by pelagic and Demersal fish species from the eastern Central Atlantic Ocean, off the coast of Ghana. Mar Pollut Bull 153:110998

2. Alexander L, Agyekumhene A, Allman P (2017) The role of taboos in the protection and recovery of sea turtles. Front Mar Sci 4:237. https://doi.org/10.3389/fmars.2017.00237

3. Alves B, Angnuureng DB, Morand P et al (2020) A review on coastal erosion and flooding risks and best management practices in West Africa: what has been done and should be done. J Coast Conserv 24:38 https://doi.org/10.1007/s11852-020-00755-7

4. Anozie C, Umahi T, Onuoha G, Nwafor N, Alozie OJ (2019) Ocean governance, integrated maritime security and its impact in the Gulf of Guinea: a lesson for Nigeria's maritime sector and economy. Afr Rev 11(2):190-207

5. Apple J, Lemus J, Semken S (2014) Teaching geoscience in the context of culture and place. J Geosci Educ 62(1):1-4

6. Arbic BK (2020) The Coastal Ocean environment Summer School in Ghana - five years of collaboration between Michigan and Ghanaian partners. University of Michigan African Studies Center, Alliances Newsletter, https://indd.adobe.com/view/ 3aad85bd-2d98-4fd8-842d-b6401 fbc4035?transition. Accessed 20 December 2020

7. Arbic BK, Müller M, Richman JG, Shriver JF, Morten AJ, Scott RB, Serazin G, Penduff T (2014) Geostrophic turbulence in the frequency-wavenumber domain: Eddy-driven low-frequency variability. J Phys Oceanogr 44:2050-2069

8. Asiedu B, Annor Baah G, Baah Annor P, Nunoo FKE, Failler P (2019) Illegal, unreported and unregulated (IUU) fishing activities on fisheries sustainability: evidence from Lake Volta, Ghana. Int J Fish Aquat Stud 7(4):14-20

9. Avtar R, Komolafe AA, Kouser A et al (2020) Assessing sustainable development prospects through remote sensing: a review. Remote Sens Appl 20:100402

10. Bakun A (1978) Guinea current upwelling. Nature 271:147-150

11. Belhabib D, Rashid Sumaila U, Le Billon P (2019) The fisheries of Africa: exploitation, policy, and maritime security trends. Mar Policy 101:80-92

12. Boateng I, Wiafe G, Jayson-Quashigah PN (2017) Mapping vulnerability and risk of Ghana's coastline to sea level rise. Mar Geod 40(1):23-39

13. Boye CB, Appeaning Addo K, Wiafe G, Dzigbodi-Adjimah K (2018) Spatio-temporal analyses of shoreline change in the Western region of Ghana. J Coast Conserv 22(4):769-776

14. Colwell RN (1997) In: Philipson WR (ed) History and place of photographic interpretation, manual of photographic interpretation, 2nd edn. American Society for Photogrammetry \& remote sensing, Bethesda, pp 33-48

15. Cuker BE (2006) Programmatic approaches to building diversity in the aquatic sciences. Mar Technol Soc J 39:13-16

16. Gill DA, Mascia MB, Ahmadia GN, Glew L, Lester SE, Barnes M et al (2017) Capacity shortfalls hinder the performance of marine protected areas globally. Nature. 543:665-669

17. Glegg G (2014) Training for marine planners: present and future needs. Mar Policy 43:13-20

18. Gu G, Adler RF (2004) Seasonal evolution and variability associated with the west African monsoon system. J Clim 17:3364-3377

19. Kganyago M, Mhangara $P$ (2019) The role of african emerging space agencies in earth observation capacity building for facilitating the implementation and monitoring of the African development agenda: the case of african earth observation program. ISPRS Int J Geo Inf 8(7):292
20. Kullenberg G (1998) Capacity building in marine research and ocean observations: a perspective on why and how. Mar Policy 22(3):185-195

21. Kurekin AA, Loveday BR, Clements O, Quartly GD, Miller PI, Wiafe G, Adu Agyekum K (2019) Operational monitoring of illegal fishing in Ghana through exploitation of satellite earth observation and AIS data. Remote Sens 11(3):293. https://doi.org/10.3390/ rs11030293

22. Lamb PJ (1978) Case studies of tropical Atlantic surface circulation pattern during recent sub- Saharan weather anomalies, 1967-1968. Mon Weather Rev 106:482-491

23. Lamptey AM, Ofori-Danson PK (2014) Review of the distribution of waterbirds in two tropical coastal Ramsar lagoons in Ghana, West Africa. West Afr J Appl Ecol 22(1):77-91

24. Miloslavich P, Seeyave S, Muller-Karger F, Bax N, Ali E, Delgado C, Evers-King H, Loveday B, Lutz V, Newton J, Nolan G, Peralta Brichtova AC, Traeger-Chatterjee C, Urban E (2019) Challenges for global ocean observation: the need for increased human capacity. J Oper Oceanogr 12(sup2):S137-S156

25. Morrison RJ, Zhang J, Urban ER, Hall J, Ittekkot V, Avril B et al (2013) Developing human capital for successful implementation of international marine scientific research projects. Mar Pollut Bull 77: $11-22$

26. Muller-Karger F et al (2013) Satellite remote sensing in support of an Integrated Ocean observing system. IEEE Geosc Rem Sen M $1(4): 8-18$

27. Naik S, Mishra RK, Panda US, Mishra M, Panigrahy RC (2020) Phytoplankton community response to environmental changes in Mahanadi estuary and its adjoining coastal waters of bay of Bengal: a multivariate and remote sensing approach. Remote Sens Earth Syst Sci 3:110-122

28. Nyadjro ES, Jensen TG, Richman JG, Shriver JF (2017) On the relationship between wind, SST, and the thermocline in the Seychelles-Chagos thermocline ridge. IEEE Geosci Remote Sens Lett 14(12):2315-2319

29. Okafor-Yarwood I, Kadagi NI, Miranda NAF, Uku J, Elegbede IO, Adewumi IJ (2020) The blue economy-cultural livelihood-ecosystem conservation triangle: the African experience. Front Mar Sci 7: 586

30. Peach C, Scowcroft G (2016) Broadening the impact of graduate education in the ocean sciences. Oceanography 29(1):60-66. https://doi.org/10.5670/oceanog.2016.14

31. Riggs EM, Kimbrough DL (2002) Implementation of constructivist pedagogy in a geoscience course designed for pre-service K-6 teachers: Progress, pitfalls, and lessons learned. J Geosci Educ 50(1):49-55

32. Ryabinin V, Barbière J, Haugan P, Kullenberg G, Smith N, McLean C, Troisi A, Fischer A, Aricò S, Aarup T, Pissierssens P, Visbeck M, Enevoldsen HO, Rigaud J (2019) The UN decade of ocean science for sustainable development. Front Mar Sci 6:470. https://doi.org/10.3389/fmars.2019.0047

33. Saraceno M, Tonini MH, Williams GN et al (2020) On the complementary information provided by satellite images, Lagrangian drifters, and a regional numerical model: a case study in the san Matias gulf, Argentina. Remote Sens Earth Syst Sci 3:123-135

34. Schollaert Uz S, Ruane AC, Duncan BN et al (2019) Earth observations and integrative models in support of food and water security. Remote Sens Earth Syst Sci 2:18-38

35. Stastny J, Cheung S, Wiafe G, Agyekum K, Greidanus H (2015) Application of RADAR corner reflectors for the detection of small vessels in synthetic aperture radar. IEEE J Sel Top Appl 8(3):1099 1107

36. Wiafe G, Nyadjro ES (2015) Satellite observations of upwelling in the Gulf of Guinea. IEEE Geosci Remote Sens Lett 12(5):10661070 
37. Wiafe G, Yaqub HB, Mensah MA, Frid CLJ (2008) Impact of climate change on long-term zooplankton biomass in the upwelling region of the Gulf of Guinea. ICES J Mar Sci 65:318-324

38. Woldai $\mathrm{T}$ (2020) The status of earth observation (EO) and geoinformation sciences in Africa - trends and challenges. Geo Spat Inf Sci 23(1):107-123

39. Croitoru L, Miranda JJ, Sarraf M (2019) The Cost of Coastal Zone Degradation in West Africa: Benin, Cote d'Ivoire, Senegal, and
Togo (English). Washington, D.C.: World Bank Group. http:// documents.worldbank.org/curated/en/822421552504665834/TheCost-of-Coastal-Zone-Degradation-in-West-Africa-Benin-CotedIvoire-Senegal-and-Togo. Accessed 6 Jan 2021

Publisher's Note Springer Nature remains neutral with regard to jurisdictional claims in published maps and institutional affiliations. 